\title{
Priority effects alter interaction outcomes in a legume-rhizobium mutualism
}

\author{
Julia A. Boyle ${ }^{1}$, Anna K. Simonsen ${ }^{2}$, Megan E. Frederickson ${ }^{1 *}$, John R. Stinchcombe ${ }^{1,3, *}$
}

(*) Equal contribution

1. Department of Ecology and Evolutionary Biology, University of Toronto, 25 Willcocks St., Toronto, ON, Canada, M5S3B2

2. Research School of Biology, Australian National University, Canberra, ACT, 2601 Australia

3. Koffler Scientific Reserve, University of Toronto, Toronto, ON Canada, M5S3B2

julia.boyle@mail.utoronto.ca, anna.simonsen@anu.edu.au,m.frederickson@utoronto.ca, john.stinchcombe@utoronto.ca

Abbreviated title: Priority effects alter mutualisms

Keywords: priority effects, mutualism, symbiosis, Medicago lupulina, rhizobia, plant-microbe interactions, legume, historical contingency

\section{Letters article}

Number of references: 58

Numbers of figures and tables: 5

Statement of authorship: JB, MF, and JS collaborated on the ideas; JB, MF, and JS designed the methodology, JB performed the experiments, and JB, AS, MF, and JS wrote and edited the manuscript. JB, MF, and JS analysed the data. All authors contributed to this manuscript and approve its publication.

Data accessibility: Data and code will be made accessible through the Dryad Data repository. Corresponding author information: Julia Boyle, julia.boyle@mail.utoronto.ca, Department of Ecology and Evolutionary Biology, University of Toronto, 25 Willcocks St., Toronto, ON, Canada, M5S3B2 


\begin{abstract}
Priority effects occur when the order of species arrival affects final community structure. Mutualists often interact with multiple partners in different orders, but if or how priority effects alter interaction outcomes is an open question. In the field, we paired the legume Medicago lupulina with two nodulating strains of Ensifer bacteria that vary in nitrogen-fixing ability. We inoculated plants with strains in different orders and measured interaction outcomes. The first strain to arrive primarily determined plant performance and final relative abundances of rhizobia on roots. Plants that received effective microbes first and ineffective microbes second grew larger than plants inoculated with the same microbes in opposite order. Our results show that mutualism outcomes can be influenced not just by partner identity, but by interaction order. Furthermore, hosts receiving high-quality mutualists early can better tolerate low-quality symbionts later, indicating priority effects may help explain the persistence of ineffective symbionts.
\end{abstract}




\section{Introduction}

Historical contingency often plays an outsized role in ecological communities, such that the order in which species arrive affects which species establish there (Fukami 2015). Current and future species composition depends on what species were already there beforehand, with previous species being facilitative or inhibitive to new ones (Fukami 2015). The effect of helping or harming future colonization is known as a priority effect, and these effects can manifest via abiotic (e.g. resource availability, space) or biotic pathways (eg. competition, trophic levels) through destabilizing or equalizing mechanisms, such as niche modification or preemption (Fukami 2015; Fukami et al. 2016). Priority effects are often studied in the assembly of plant communities during succession or with invasive species (Dickson et al. 2012). There is less research on how priority effects influence microbial community assembly on a host, or how they change host-microbe interaction outcomes (Fitzpatrick et al. 2018). Priority effects are especially likely to occur if there is variation in a microbe's quality as a partner to their host. We tested if priority effects change the outcome of a plant-bacteria symbiosis by manipulating the order of arrival of different bacteria to a plant host, and then measuring the consequences for subsequent bacterial colonization and plant performance.

A classic assumption in microbial ecology is that bacteria are not dispersal-limited over space and time, described as the Baas-Becking hypothesis (Beijerinck 1913; Baas-Becking 1934), and thus historical contingency is unimportant (see more in Martiny et al. 2006). While some species of bacteria have global distributions, at a local scale the distribution of microbes can be patchy (Reynolds et al. 2003; Martiny et al. 2011). Newer work suggests species sorting, bacterial traits and relatedness, dispersal limitation, regional differences, and seasonal variation 
can all contribute to variation in bacterial communities in both water and soil (Wolsing \& Priemé 2004; Martiny et al. 2011; Lindström \& Langenheder 2012). A well known example of a bacterial community likely experiencing priority effects is the human gut microbiome, which is strongly shaped by diet and parental care when young (Sprockett et al. 2018). Just as human beings host their own communities, plant hosts act as selective microcosms of their larger microbial landscape (Fitzpatrick et al. 2018). There exists spatial differences in bacterial species (Patterson 2009) that can contribute to temporal differences in plant microbial communities (Woody et al. 2007), ultimately creating an environment where priority effects could occur.

Of the existing research on host-associated microbial priority effects, most center on fungi-plant interactions (Johnson 2015). Arbuscular mycorrhizal fungi show evidence of priority effects with the legume Medicago truncatula; when M. truncatula roots are already colonized, subsequent colonization decreases, and the decrease is more drastic the longer the time gap is between fungus treatments (Werner \& Kiers 2015). However, Werner and Kiers (2015) did not observe strong priority effects on plant performance from treatments applying two mutualistic fungi in different orders. Ectomycorrhizal fungi may also experience priority effects in colonizing their hosts when they are introduced with a time lag (Kennedy \& Bruns 2005; Kennedy et al. 2009), nonetheless the effect on host performance remains less clear. These studies demonstrate the importance of priority effects to fungal microbial communities, and raise the same question of whether priority effects are seen in other symbiotic microbes, such as nitrogen-fixing rhizobial bacteria and their legume hosts.

Legumes house rhizobacteria within specialized root structures called nodules, providing the bacteria with fixed carbon in exchange for fixed nitrogen. Most rhizobia are effective 
nitrogen-fixers, but not all are equally beneficial to their host plants (Lepinay et al. 2012), and there is a wide range of potential partners for the symbiosis. Effective nitrogen-fixing bacteria are mutualistic, while others may provide few benefits to hosts or over-exploit plant resources (Denison 2000; Porter et al. 2018); however, less effective rhizobia can still be better than no rhizobia for hosts. The maintenance of variation in mutualist partners has long been identified as an important evolutionary question (Axelrod \& Hamilton 1981; Herre et al. 1999; Heath \& Stinchcombe 2014). Coexistence theory describes how priority effects can determine the outcome of competition (Ke \& Letten 2018; Grainger et al. 2019) and hence the potential for low-quality partners to be maintained (Yu 2001; Johnson \& Bronstein 2019). Despite the theoretical importance of priority effects, how and whether hosts mediate the outcome of priority effects between mutualistic symbionts is still poorly understood and requires empirical data. To our knowledge no study has explicitly tested whether priority effects occur in one of the most well-studied and ecologically and economically important mutualisms, the legume-rhizobium symbiosis.

Here, we tested if the order of introduction of different nodule-forming bacteria strains (with known nitrogen-fixing qualities) affects bacterial colonization of hosts and host performance in the field. In the absence of priority effects, microbial communities on hosts should converge on the same abundance and identity of species, no matter which strain came first. Alternatively, effective nitrogen-fixing bacteria could facilitate plant colonization by other bacteria through niche modification, because plants with effective rhizobia are more vigorous, have greater resources, and can thus support a higher biomass of later-colonising bacteria, even if these secondary arrivals are non-beneficial or exploitative. Or, effective nitrogen-fixing 
symbionts might reduce the need for a plant to make more nodules, thus suppressing future nodulation and inhibiting colonization by other bacteria. The latter hypothesis is suggested by extensive research into the auto-regulation of nodulation (Pierce \& Bauer 1983; Kosslak \& Bohlool 1984; Schnabel et al. 2005; Magori \& Kawaguchi 2009), a signaling mechanism whereby legumes reduce nodule formation when they already have sufficient nitrogen. Ineffective nitrogen-fixing bacteria could also facilitate or inhibit future colonization by exploiting the plant, another instance of potential niche modification, since plants might accept more bacteria to fill their increased resource needs, or alternatively, ineffective symbionts might make the plant too small or weak to support other bacteria, or preemptively fill the root niche. Given these contrasting possibilities, the direction of any priority effects is an open empirical question.

\section{Methods}

Study System. We studied Medicago lupulina, an annual legume that forms indeterminate root nodules with rhizobia. Medicago lupulina seeds were collected from the Koffler Scientific Reserve (KSR) in Ontario, Canada in 2008, and to avoid maternal and plant genotype effects, in this experiment, we used seeds from a single plant genotype that had been selfed for two generations in the University of Toronto greenhouses. We inoculated plants with two strains of bacteria with different nitrogen-fixing abilities: mutualistic Ensifer meliloti strain 1022 (Terpolilli et al. 2013), and ineffective Ensifer sp. strain T173 (Bromfield et al. 2010). Ensifer meliloti strain 1022 was first isolated from Medicago orbicularis growing wild in Greece (Terpolilli et al. 2013) but the species has been found associating with M. lupulina in natural populations at KSR (Batstone et al. 2020a), while Ensifer T173 was first isolated in Melilotus 
alba growing wild in Canada, co-occurring in areas with M. lupulina (Bromfield et al. 2010). As described in previous experimental work, Ensifer sp. strain T173 has a symbiotic plasmid, but poor symbiotic effectiveness, meaning the many small, white nodules it forms on roots do not fix nitrogen (Bromfield et al. 2010). Compared to uninoculated plants, plants inoculated with only Ensifer T173 showed increased mortality, reduced plant biomass, and increased time to flowering, demonstrated in both glasshouse conditions (Simonsen \& Stinchcombe 2014a) and field conditions in previous inoculation experiments (Simonsen \& Stinchcombe 2014b).

Seed preparation and planting. First, we scarified 270 M. lupulina seeds, immersed them in ethanol for 30 seconds, bleached them for 4 minutes, and then rinsed them in distilled water for 5 minutes. We next soaked the seeds in distilled water for another 30 minutes, before placing them on sterile agar plates which were left in a completely dark environment at $4^{\circ} \mathrm{C}$. After one week of stratification, the seeds sat at room temperature for 12 hours to germinate roots at least $1 \mathrm{~cm}$ long, and then we exposed them to sunlight for an hour to promote chlorophyll production. On May 23rd, 2019, we planted seeds individually into $10 \times 10 \times 10 \mathrm{~cm}$ pots that had been bleach-sterilized, bottom-lined with landscape fabric to cover drainage holes, and filled with autoclaved sand. Sand filled the pot to within $1.25 \mathrm{~cm}$ from the top, leaving a lip. We fertilized germinants twice: a $1 \mathrm{~mL}$ low-nitrogen fertilizer dose (recipe in Supplementary Material) on the same day they were planted in the greenhouse, followed by a second dose 16 days later. Pots were initially covered in saran-wrap and kept in clear plastic bins in the Koffler Scientific Reserve greenhouse; we used the saran-wrap and plastic bins to ensure high humidity during seedling establishment and reduce early colonization by non-focal microbes. On June 7 th (15 days after germination), we planted the pots into holes in the ground in a natural grassy field at 
the Koffler Scientific Reserve. We transplanted pots into a randomized, blocked design, with two spatial blocks of 135 pots each placed into a grid, with grid rows and columns separated by 30 $\mathrm{cm}$. We placed pots into the holes so that the lip of the pot was $1.25 \mathrm{~cm}$ above ground, ensuring that the pot sand and exterior soil were flush. The lip provided a small barrier between the sand and any soil and water contamination.

Microbial treatments. Each bacterial inoculation contained the same cell densities (optical density, OD600, of 0.08 ODU for all inoculations) of bacteria suspended in TY liquid media. We gave each plant $1 \mathrm{~mL}$ of inoculum each round. To experimentally create the potential for priority effects, we separated the first and second rounds of inoculation by two weeks. We implemented a full 3 x 3 factorial design, with early inoculations of either Ensifer meliloti 1022, Ensifer sp. T173, or a control TY media inoculation, fully crossed with later inoculations of either 1022, T173, or control TY media. Consequently, there were 9 treatments with 30 plants per treatment. We added the first inoculation on June 6th 2019, the night prior to the plants being moved outside, and we then kept each of the bacterial treatment groups in separate bins overnight to avoid contamination among treatments. We administered the second inoculation on June 20th into the sand of the pots in the field, during a period of sunny days to avoid rain washing out the treatments. Bacteria in the soil may have colonized our experimental plants, but any significant treatment effects would suggest that experimental inoculations of bacteria nonetheless infected host plants, despite competition with soil bacteria.

Data collection. We counted leaves and checked for mortality after we placed pots in the field to monitor growth on June 7 th, 17th, 20th, 25th, and July 7 th and 22nd. The final leaf count was assessed by tracking the total number of leaves the plant produced throughout its life. We 
harvested plants on July 22nd and kept them in a refrigerator until we collected nodules the following week. We harvested plants prior to flowering to avoid nodule senescence (Kijne 1975, Bethlenfalvay \& Phillips 1977). We counted all nodules from each plant that survived to the end of the experiment and identified them as containing effective or ineffective nitrogen-fixing bacteria based on color, pink being indicative of nitrogen fixation (following Simonsen and Stinchcombe 2014a). Finally, we separated the aboveground biomass, dried it at $55^{\circ} \mathrm{C}$ for 48 hours, and weighed it as an indicator of overall plant performance.

Data analysis. We analyzed data in R version 3.5.3 (R Core Team 2019). In general, we used linear models with the initial microbial treatment, the subsequent microbial treatment, and their interaction as fixed predictors; exceptions or additional covariates are described below. If the first strain or the interaction was significant, this suggested priority effects occurred. We initially included block as a random effect in linear models using the lme4 (Bates et al. 2015) and lmerTest (Kuznetsova et al. 2017) packages, but subsequently excluded block when it explained zero variance. We set the reference group to be the control (i.e., sham-inoculated) treatment in all models. All ANOVAs were Type III ANOVAs, calculated in the car package (Fox \& Weisberg, 2011), unless otherwise specified. Plants that died during the experiment often had no aboveground biomass or nodules (excluded from relevant analyses), however if roots were intact by the harvest date, the number of nodules could still be assessed. To improve normality, we log-transformed nodule numbers, after adding 1 to make all values positive, non-zero numbers. To test the relative abundances of strains in nodules at the end of the experiment, we used a MANOVA followed by separate linear models for effective and ineffective nodule number. Additionally, we used emmeans (Lenth 2020) for a priori planned contrast between plants 
receiving Ensifer meliloti strain 1022 first followed by Ensifer sp. strain T173 and plants receiving these same strains in the opposite order. Aboveground biomass had non-normal residuals even after log-transformation, so we used a generalized linear mixed model with a Gamma error distribution instead. Finally, to evaluate if the order of inoculation affected plant mortality we used two Chi-Squared tests with either first or second inoculation treatment as a predictor variable.

\section{Results}

Mortality was significantly predicted by the first inoculation $\left(\chi_{2}^{2}=7.28, p<0.05\right)$ but the second inoculation had no effect $\left(\chi_{2}^{2}=0.121, \mathrm{p}=0.94\right)$. Differences in mortality among treatments were mainly because of reduced mortality of plants treated with strain 1022 at the first inoculation. Plants that received 1022 as the first inoculum had 27.7\% mortality, while those that received T173 first had $36 \%$ mortality, and those that received the control first had $46.6 \%$ mortality. The T173-1022 treatment had 40\% mortality, compared to only $16.6 \%$ mortality in the $1022-\mathrm{T} 173$ treatment.

The total number of nodules on a plant differed depending on which treatment it received first, second, and their interaction (Table 1, Figure 1). Plants made significantly more nodules when given a bacterial inoculation compared to blank media, even when plants received the ineffective strain (Figure 1). The uninoculated control plants had significantly fewer nodules than all other treatments (Figure 1). However, a planned contrast found no significant difference in the number of nodules produced by plants in the 1022-T173 versus T173-1022 treatments 
$(\mathrm{p}=0.194)$. Plants receiving T173 made more nodules than plants that did not receive T173, regardless of strain order (planned contrast, $\mathrm{p}=0.001$ ).

The number of effective and ineffective nodules differed based on order of arrival, even between plants that got 1022 first and T173 second (83.0\% effective nodules) and plants that got T173 first and 1022 second (57.6\% effective nodules) (Figure 2). The MANOVA with both effective and ineffective nodule numbers found significant effects of strain at time 1, strain at time 2, and their interaction (Table 2), even when accounting for the potential correlation between effective and ineffective nodules. Therefore, the rhizobia strains a plant received affected relative strain abundance, as well as the order in which they arrived. Notably, we found ineffective nodules only on plants that received T173, and plants that received only $\mathrm{T} 173$ had the highest proportion of ineffective nodules (Figure 2). In the linear model of the number of ineffective nodules, there were significant effects of strain at the first time point, strain at the second time point, and the order of arrival, with T173 increasing the number of ineffective nodules at both time points, but non-additively (Table 2). The number of ineffective nodules was significantly higher in the T173-1022 treatment than in the 1022-T173 treatment in a planned contrast $(\mathrm{p}=0.008)$. Thus, getting 1022 first inhibited the formation of nodules with the ineffective strain, T173. In contrast, the number of nitrogen-fixing nodules was only significantly predicted by the first inoculation (Table 2), such that plants that got 1022 then T173 made significantly more effective nodules than plants that got T173 then 1022 (planned contrast, $\mathrm{p}=0.017$ ). When a plant was given a 1022 inoculation at any time, more than half of its nodules were likely to be effective, even if it received T173 earlier or later. 
Aboveground biomass significantly differed depending on the first strain plants received (Table 1) with getting 1022 first leading to the highest aboveground biomass (Figure 3). The 1022-T173 treatment had the highest mean aboveground biomass whereas the lowest was T173-1022, and this was significant in the planned contrast $(\mathrm{p}=0.009)$. Receiving T173 first led to the lowest aboveground biomass, even if they were inoculated with 1022 later (Figure $3 \&$ Supplementary Figure 1). The number of nitrogen-fixing nodules was significantly, positively correlated with aboveground biomass (Adjusted $\mathrm{R}^{2}=0.277, \mathrm{p}<0.001$, Supplementary Figure 2), but the number of ineffective nodules was not correlated with aboveground biomass (Adjusted $\mathrm{R}^{2}=0.0058, \mathrm{p}=0.15860$, Supplementary Figure 3). Leaf number through time showed patterns similar to aboveground biomass and the rank order of treatments stayed consistent after inoculation with the first strain, suggesting little effect of the second strain (Supplementary Figure 4).

\section{Discussion}

We found evidence of priority effects in rhizobial colonization of M. lupulina under field conditions, and these priority effects impacted the outcome of this plant-bacteria symbiosis. The order of arrival of two Ensifer strains affected plant performance, nodulation, and the relative abundance of strains at the end of the experiment (i.e., final community composition), with the first strain added being the most influential. Furthermore, receiving the ineffective strain first made the mutualist strain less effective when it arrived later, while receiving the mutualist strain first prevented the ineffective strain from exploiting the plant and reducing plant performance. 
Priority effects help or hinder future species colonization via two mechanisms: niche preemption or niche modification (Fukami 2015). In our experiment, the niche being filled is the plant root, with rhizobia being the colonizing species. We observed that the order of arrival of T173-1022 versus 1022-T173 did not affect how much of the niche was being used (i.e. total number of infection sites on the roots), since the difference in nodule number was non-significant between those treatments. Despite similar amounts of the niche being occupied, strain relative abundances differed, suggesting niche preemption, with one species preemptively using the resources that another species would need to successfully colonize (Eisenhauer et al. 2012; Mendes et al. 2014; Fukami et al. 2016). Interpreting our results as niche preemption is also congruent with the auto-regulation of nodulation (a process where legumes have an ability to reduce or limit the number of nodules they produce (Ferguson et al. 2010; Lagunas et al. 2019)), since both mechanisms suggest that past interactions between a host plant and microbes determines if later microbes can successfully colonize. When T173 was the first strain, it filled more of the available niche than when it arrived second, and vice versa for 1022 (Figure 2). Nonetheless, the better strain (1022) was better at excluding T173 than the other way around, since the 1022-T173 had less than 20\% ineffective nodules while the T173-1022 had over 50\% effective nodules (Figure 2).

The implications of microbial priority effects for host benefits are important but have received little attention. Plant performance was determined by the first strain the plant received, suggesting early exposure to symbionts is especially influential (Horsfall \& Cowling 1978; Wani et al. 2015). When plants have early exposure to effective N-fixers, plant performance is improved irrespective of the quality of later symbionts (Figure 3), suggesting 
priority effects help determine the benefits a microbiome confers to its host. Hosts may be under strong selection to associate with an effective mutualist as soon as possible in their lifecycle. Once associated, legumes with different quality symbionts may be considered as modified niches for microbes, with different nodulation responses (Figure 1) and quantity and quality of resources (Whiteside et al. 2019). Priority effects could therefore alter the local competitive dynamic of hosts with other plants, and hosts' interactions with other species; for example, increased plant nitrogen (provisioned by bacteria) may increase herbivory (Simonsen \& Stinchcombe 2014b), or greater biomass may increase flower number and thus pollination (Klinkhamer et al. 1989). On a broader scale, the composition and abundance of soil microbes are heterogeneous across space, and may change seasonally (Wolsing \& Priemé 2004), providing opportunities for priority effects to affect the success and distribution of plants across the landscape. When a plant colonizes a new site, associating with an effective partner first may mitigate costs of associating with less-effective partners later that may not be adapted to the host. In contrast, when a plant colonizes an environment where effective partners are less frequent, the plant could associate with ineffective partners first and experience priority effects that reduce its performance regardless of future effective partners, constraining plant distribution.

The result that microbial priority effects can influence the outcome of a mutualism is relevant to the maintenance of variation in mutualist quality. We know high-quality partners may be maintained by positive fitness feedbacks or partner discrimination mechanisms (Weyl et al. 2010; Frederickson 2013), but the existence and maintenance of low-quality partners is less well understood (Heath \& Stinchcombe 2014). Simonsen and Stinchcombe (2014b) previously showed that insect herbivores could help maintain low-quality partners, because herbivores 
preferentially attacked legumes inoculated with effective $\mathrm{N}$-fixing rhizobia thus eliminating fitness differences between plants with high- and low-quality bacterial partners. We have shown that priority effects at the level of an individual plant may promote larger-scale maintenance of variation in mutualist quality, since plant and microbial fitness depend not only on what microbes colonized each plant, but what order they arrived in. Ineffective symbionts extensively colonized M. lupulina roots, but only when they arrived early (Figure 2). Furthermore, in our experiment, early exposure to an effective mutualist reduced the costs of acquiring an ineffective partner later (note similarity between 1022-1022 and 1022-T173 in Figure 3), which may weaken selection against the ineffective partner and help it persist in the community. However, the opposite still occurs, where exposure to an ineffective partner first reduces the performance benefits of a good mutualist later on. Additionally, colonization-competition trade-offs (Smith et al. 2018) could support the idea that a poor-quality partner that makes many nodules but has low competitive ability in the soil, such as Ensifer sp. T173, can coexist alongside a higher-quality partner that makes fewer nodules but has higher competitive ability, such as Ensifer meliloti 1022. A recent evolution experiment found that $E$. meliloti 1022 rapidly out-competed another low-quality strain (Batstone et al. 2020b), and non-N-fixing nodulating partners appear to be rare at our field site, given that some effective but no ineffective nodules were formed on control plants in our experiment (Figure 2).

There were fairly low levels of colonization of rhizobia present in the field soil on our experimental plants, suggesting our treatments were effective. Plants that received only sham inoculations had the fewest nodules, and all were pink, nitrogen-fixing nodules; this suggests T173 did not travel between pots, and again, that the naturally occurring rhizobia in the soil are 
N-fixing. The absence of T173 in the environmental soil matches a previous study that sequenced naturally occuring rhizobia from Medicago lupulina nodules collected at the same field site (Batstone et al. 2020a) and found that most nodules contained Ensifer meliloti, or another effective symbiont, Ensifer medicae (Harrison et al. 2017). Our results show that priority effects can occur under field conditions, and there are myriad ways that strains might arrive in different orders on plants in natural populations: for example, with rain moving rhizobia from site to site, existing patchiness of soil microbes, or the death of a legume releasing a pulse of rhizobia from its roots. How priority effects play out in more diverse microbial communities in the soil, which often have more than just two rhizobial strains, remains to be seen, but our results suggest that plant fitness may be strongly shaped by which microbe(s) colonize it first.

Current intense interest in microbiomes means it is more important than ever to understand how microbial communities assemble on hosts, and how microbial community assembly affects interaction outcomes and host health. We showed that priority effects strongly influenced microbial colonization of hosts and the outcome of host-microbe interactions, with hosts benefiting more from getting an effective symbiont early. Most mutualisms and microbiomes are horizontally transmitted; they typically assemble anew on hosts that begin their lives with few, if any, microbes. Our results suggest that the first microbes to colonize hosts might have long-lasting effects, and largely determine host benefits and subsequent microbial community assembly. 


\section{Acknowledgements}

We thank Tia Harrison for her help and knowledge for all things Medicago, and Dale Pebesma for assistance in the field. We also thank Kate Brown, Will Sturch, and John Jensen at the Koffler Scientific Reserve (2019), and Agriculture Canada, Jason Terpolilli, and Rebecca

Batstone for sharing rhizobial strains. This work was funded by the Natural Sciences and Engineering Research Council of Canada, specifically Discovery Grants to MF and JS, and a USRA to JB.

\section{Literature Cited}

Axelrod, R. \& Hamilton, W. D. (1981). The evolution of cooperation. Science, 211(4489), 1390-1396.

Baas-Becking, L.G.M., (1934). Geobiologie; of inleiding tot de milieukunde. W.P. Van Stockum \& Zoon.

Beijerinck, M.W., (1913). De infusies en de ontdekking der backteriën. Jaarboek van de Koninklijke Akademie voor Wetenschappen. Amsterdam: Müller.

Bates, D., Mächler, M., Bolker, B. \& Walker, S. (2015). Fitting Linear Mixed-Effects Models Using lme4. J. Stat. Softw, 67, 1-48.

Batstone, R. T., Peters, M. A. E., Simonsen, A.K., Stinchcombe, J.R. \& Frederickson, M.E. (2020a). Environmental variation impacts trait expression and selection in the legume-rhizobium symbiosis. Am. J. Bot, 107, 195-208. 
Batstone, R.T., O’Brien, A.M., Harrison, T.L. \& Frederickson, M.E. (2020b). Experimental evolution makes microbes more cooperative with their local host genotype. Science, 370(6515), 476-478.

Bethlenfalvay, G. J. \& Phillips, D.A. (1977). Ontogenetic Interactions between Photosynthesis and Symbiotic Nitrogen Fixation in Legumes. Plant physiol, 60, 419-21.

Bromfield, E. S. P., Tambong, J. T., Cloutier, S., Prévost, D., Laguerre, G., van Berkum, P., Tran Thi, T.V., et al. (2010). Ensifer, Phyllobacterium and Rhizobium species occupy nodules of Medicago sativa (alfalfa) and Melilotus alba (sweet clover) grown at a Canadian site without a history of cultivation. Microbiology, 156, 505-520.

Denison, R. F. \& Kiers, E.T. (2004). Why are most rhizobia beneficial to their plant hosts, rather than parasitic? Microbes and Infect, 6, 1235-1239.

Dickson, T. L., Hopwood, J. L. \& Wilsey, B. J. (2012). Do priority effects benefit invasive plants more than native plants? An experiment with six grassland species. Biol. Invasions, 14, 2617-2624.

Eisenhauer, N., Schulz, W., Scheu, S. \& Jousset, A. (2012). Niche dimensionality links biodiversity and invasibility of microbial communities. Funct. Ecol, 27(1), 282-288.

Ferguson, B.J., Indrasumunar, A., Hayashi, S., Lin, M., Lin, Y., Reid, D.E. \& Gresshoff, P.M. (2010). Molecular Analysis of Legume Nodule Development and Autoregulation. J. Integr. Plant Biol, 52(1), 61-76. 
Fitzpatrick, C. R., Copeland, J., Wang, P. W., Guttman, D. S., Kotanen, P. M. \& Johnson, M. T. J. (2018). Assembly and ecological function of the root microbiome across angiosperm plant species. Proc. Natl. Acad. Sci. U. S. A, 115, E1157-E1165.

Fox, J. \& Weisberg, S. (2011). An R companion to applied regression (2nd ed.). Thousand Oaks CA: Sage Publications.

Frederickson, M.E. (2013). Rethinking Mutualism Stability: Cheaters and the Evolution of Sanctions. Q Rev Biol, 88(4), 269 - 295.

Fukami, T. (2015). Historical Contingency in Community Assembly: Integrating Niches, Species Pools, and Priority Effects. Annu. Rev. Ecol. Evol. Syst, 46, 1-23.

Fukami, T., Mordecai, E. A., Ostling, A. \& Mordecai, E.A. (2016). A framework for priority effects. J. Vege. Sci, 27, 655-657.

Grainger, T.N. Letten, A.D., Gilbert, B. \& Fukami, T. (2019). Applying modern coexistence theory to priority effects. Proc. Natl. Acad. Sci. U.S.A, 116(13), 6205-6210.

Harrison, T.L., Wood, C.W., Heath, K.D. \& Stinchcombe, J.R. (2017). Geographically structured genetic variation in the Medicago lupulina-Ensifer mutualism. Evolution, 71(7), 1787-1801.

Heath, K. D. \& Stinchcombe, J.R. (2014). Explaining mutualism variation: a new evolutionary paradox? Evolution, 68, 309-317.

Herre, E. A., Knowlton, N., Mueller, U.G. \& Rehner, S.A. (1999). The evolution of mutualisms: Exploring the paths between conflict and cooperation. Trends Ecol. Evol, 14(2), 49-53. 
Horsfall, J. G. \& Cowling, E.B. (1978). Plant disease : an advanced treatise. Volume II, How disease develops in populations. Academic Press.

Johnson, D. (2015). Priorities for research on priority effects. New Phytol, 205, 1375-1377.

Johnson, C. \& Bronstein, J.L. (2019). Coexistence and competitive exclusion in mutualism. Ecology, 100(6), e02708.

Ke, P. \& Letten, A.D. (2018). Coexistence theory and the frequency-dependence of priority effects. Nat. Ecol. Evol, 2, 1691-1695.

Kennedy, P. G. \& Bruns, T.D. (2005). Priority effects determine the outcome of ectomycorrhizal competition between two Rhizopogon species colonizing Pinus muricata seedlings. New Phytol, 166, 631-638.

Kennedy, P. G., Peay, K.G. \& Bruns, T.D. (2009). Root tip competition among ectomycorrhizal fungi: Are priority effects a rule or an exception? Ecology, 90, 2098-2107.

Kijne, J. W. (1975). The fine structure of pea root nodules. 2. Senescence and disintegration of the bacteroid tissue. Physiol. Plant Pathol, 7, 17-21.

Klinkhamer, P.G.L., de Jong, T.J. \& de Bruyn, G. (1989). Plant Size and Pollinator Visitation in Cynoglossum Officinale. Oikos, 54(2), 201-204.

Kosslak, R.M. \& Bohlool, B.B. (1984). Suppression of nodule development of one side of a split-root system of soybeans caused by prior inoculation of the other side. Plant Physiol, 75, 125-130. 
Kuznetsova, A., Brockhoff, P.B. \& Christensen, R. H. B. (2017). lmerTest Package: Tests in Linear Mixed Effects Models . J. Stat. Softw, 82, 1-26.

Lagunas, B., Achom, M., Bonyadi-Pour, R., Pardal, A.J., Richmond, B.L., Sergaki, C., Vázquez, S., Schäfer, P., Ott, S., Hammond, J. \& Gifford, M.L. (2019). Regulation of Resource Partitioning Coordinates Nitrogen and Rhizobia Responses and Autoregulation of Nodulation in Medicago truncatula. Mol Plant, 12(6), 833-846.

Lenth, R. (2020). emmeans: Estimated Marginal Means, aka Least-Squares Means. R package version 1.5.1. https://CRAN.R-project.org/package=emmeans

Lepinay, C., Rigaud, T., Salon, C., Lemanceau, P. \& Mougel, C. (2012). Interaction between Medicago truncatula and Pseudomonas fluorescens: Evaluation of Costs and Benefits across an Elevated Atmospheric CO2. PLoS ONE, 7, e45740.

Lindström, E. S. \& Langenheder, S. (2012). Local and regional factors influencing bacterial community assembly. Environ Microbiol Rep, 4, 1-9.

Magori, S. \& Kawaguchi, M. (2009). Long-Distance Control of Nodulation: Molecules and Models. Mol. Cells, 27, 129-134.

Martiny, J. B. H., Bohannan, B. J. M., Brown, J.H., Colwell, R. K., Fuhrman, J. A., Green, J. L., Horner-Devine, M.C, et al. (2006). Microbial biogeography: Putting microorganisms on the map. Nat. Rev. Microbiol, 112, 102-112. 
Martiny, J. B. H., Eisen, J. A., Penn, K., Allison, S.D. \& Horner-Devine, M.C. (2011). Drivers of bacterial $\beta$-diversity depend on spatial scale. Proc. Natl. Acad. Sci. U. S. A, 108, 7850-7854.

Mendes, L.W., Kuramae, E.E., Navarrete, A.A., van Veen, J.A. \& Tsai, S.M. (2014).

Taxonomical and functional microbial community selection in soybean rhizosphere. ISME J, 8 , 1577-1587.

Patterson, D. J. (2009). Seeing the Big Picture on Microbe Distribution. Science, 325, 1506 $-1507$.

Pierce, M. \& Bauer, W.D. (1983). A Rapid Regulatory Response Governing Nodulation in Soybean. Plant Physiol, 73, 286-290.

Porter, S. S., Faber-Hammond, J., Montoya, A.B., Friesen, M.L. \& Sackos, C. (2019). Dynamic genomic architecture of mutualistic cooperation in a wild population of Mesorhizobium. ISME J, 13, 301-315.

Reynolds, H. L., Packer, A., Bever, J.D. \& Clay, K. (2003). Grassroots ecology: plant-microbe-soil interactions as drivers of plant community structure and dynamics. Ecology, 84, 2281-2291.

R Core Team. (2019). R: A language and environment for statistical computing. R Foundation for Statistical Computing, Vienna, Austria. URL https:/www.R-project.org/. 
Schnabel, E., Journet, E.P., De Carvalho-Niebel, F., Duc, G. \& Frugoli, J. (2005). The Medicago truncatula SUNN gene encodes a CLV1-like leucine-rich repeat receptor kinase that regulates nodule number and root length. Plant Mol Biol, 58, 809-822.

Simonsen, A. K. \& Stinchcombe, J.R. (2014a). Standing genetic variation in host preference for mutualist microbial symbionts. Proc. R. Soc. B, 281, 20142036.

Simonsen, A. K. \& Stinchcombe, J.R. (2014b). Herbivory eliminates fitness costs of mutualism exploiters. New Phytol, 202, 651-661.

Singleton, P. W. \& Stockinger, K.R. (1983). Compensation against Ineffective Nodulation in Soybean. Crop Sci, 23, 69.

Smith, G.R., Steidinger, B.S., Bruns, T.D. \& Peay, K.G. (2018). Competition-colonization tradeoffs structure fungal diversity. ISME J, 12(7), 1758-1767.

Sprockett, D., Fukami, T. \& Relman, D.A. (2018). Role of priority effects in the early-life assembly of the gut microbiota. Nat. Rev. Gastroenterol. Hepatol, 15, 197-205.

Terpolilli, J., Hill, Y., Tian, R., Howieson, J., Bräu, L., Goodwin, L., Han, J. et al. (2013). Genome sequence of Ensifer meliloti strain WSM1022; a highly effective microsymbiont of the model legume Medicago truncatula A17. Stand. Genom. Sci, 9, 315.

Wani, Z.A, Ashraf, N., Mohiuddin, T. \& Riyaz-Ul-Hassan, S. (2015). Plant-endophyte symbiosis, an ecological perspective. Appl. Microbiol. Biotechnol, 99, 2955-2965. 
Werner, G. D. A. \& Kiers, E.T. (2015). Order of arrival structures arbuscular mycorrhizal colonization of plants. New Phytol, 205, 1515-1524.

Weyl, E.G., Frederickson, M.E., Yu, D.W. \& Pierce, N.E. (2010). Economic contract theory tests models of mutualism. Proc. Natl. Acad. Sci. U. S. A, 107(36), 15712-6.

Whiteside, M.D., Werner, G.D.A, Caldas, V.E.A, van’t Padje, A., Dupin, S.E., Elbers, B., et al. (2019). Mycorrhizal Fungi Respond to Resource Inequality by Moving Phosphorus from Rich to Poor Patches across Networks. Curr. Biol, 29, 2043-2050.

Wolsing, M. \& Priemé, A. (2004). Observation of high seasonal variation in community structure of denitrifying bacteria in arable soil receiving artificial fertilizer and cattle manure by determining T-RFLP of nir gene fragments. FEMS Microbiol. Ecol, 48(2), 261-271.

Woody, S. T., Ives, A.R., Nordheim, E.V. \& Andrews, J.H. (2007). Dispersal, density dependence, and population dynamics of a fungal microbe on leaf surfaces. Ecology, 88, $1513-1524$.

Yu, D. W. (2001). Parasites of mutualisms. Biol. J. Linn. Soc, 72, 529-546. 


\section{Tables \& Figures}

Table 1. Linear model for nodulation and generalized linear mixed model for plant performance.

The reference group is the control-control treatment. F and $\mathrm{p}$ values are from the type III ANOVAs. The GLMM used a Gamma error distribution.

\begin{tabular}{|c|c|c|c|c|c|c|c|c|c|c|}
\hline & \multicolumn{5}{|c|}{ Total nodules (no.) } & \multicolumn{5}{|c|}{ Aboveground biomass (g) } \\
\hline Predictors & Estimate & Error & $F$ & $d f$ & $p$ & Estimate & Error & Wald $X^{2}$ value & $d f$ & $p$ \\
\hline Intercept & 1.25 & 0.185 & 45.2 & 1,178 & $<0.001$ & 75.9 & 13.9 & 29.7 & 1 & $<0.001$ \\
\hline $\begin{array}{c}\text { First strain } \\
\text { T173 }\end{array}$ & 1.26 & 0.242 & 13.5 & 2,178 & $<0.001$ & 34.1 & 22.1 & 6.89 & 2 & 0.0319 \\
\hline $\begin{array}{c}\text { First strain } \\
1022\end{array}$ & 0.703 & 0.242 & & & & -14.7 & 16.6 & & & \\
\hline $\begin{array}{c}\text { Second } \\
\text { strain T173 }\end{array}$ & 0.544 & 0.276 & 3.00 & 2,178 & 0.0525 & 22.4 & 24.3 & 0.896 & 2 & 0.638 \\
\hline $\begin{array}{c}\text { Second } \\
\text { strain } 1022\end{array}$ & 0.558 & 0.249 & & & & 11.9 & 19.1 & & & \\
\hline T173:T173 & -0.889 & 0.358 & 3.06 & 4,178 & 0.0181 & -40.4 & 34.1 & 1.49 & 4 & 0.828 \\
\hline 1022:T173 & -0.147 & 0.352 & & & & -22.7 & 27.5 & & & \\
\hline T173:1022 & -1.01 & 0.338 & & & & -11.5 & 31.6 & & & \\
\hline $1022: 1022$ & -0.431 & 0.340 & & & & -3.69 & 23.5 & & & \\
\hline
\end{tabular}


Table 2. MANOVA and linear model results for effective and ineffective nodule numbers. The reference group is the control-control treatment. F and $\mathrm{p}$ values are from the type III ANOVAs. Linear model results are shown in the 'Effective' and 'Ineffective' nodule columns.

\begin{tabular}{|c|c|c|c|c|c|c|c|c|c|c|c|c|c|}
\hline \multirow{3}{*}{ Predictors } & \multicolumn{13}{|c|}{ Strain relative abundances } \\
\hline & \multicolumn{5}{|c|}{ Effective nodules (no.) } & \multicolumn{5}{|c|}{ Ineffective nodules (no.) } & \multicolumn{3}{|c|}{ MANOVA } \\
\hline & Estimate & Error & $F$ & $d f$ & $p$ & Estimate & Error & $F$ & $d f$ & $p$ & $F$ & $d f$ & $p$ \\
\hline Intercept & 1.15 & 0.170 & 45.8 & 1,183 & $<0.001$ & $-3.85 e-16$ & $1.20 \mathrm{e}-01$ & 0.00 & 1,183 & 1 & & & \\
\hline $\begin{array}{c}\text { First strain } \\
\text { T173 }\end{array}$ & 0.218 & 0.235 & 13.6 & 2,183 & $<0.01$ & 2.15 & $1.67 \mathrm{e}-01$ & 114 & 2,183 & $<0.001$ & 54.5 & 4,356 & $<0.001$ \\
\hline $\begin{array}{c}\text { First strain } \\
1022\end{array}$ & 0.799 & 0.235 & & & & $7.75 \mathrm{e}-16$ & $1.67 \mathrm{e}-01$ & & & & & & \\
\hline $\begin{array}{l}\text { Second strain } \\
\text { T173 }\end{array}$ & -0.0181 & 0.272 & 2.54 & 2,183 & $<0.05$ & 1.32 & $1.93 \mathrm{e}-01$ & 28.8 & 2,183 & $<0.001$ & 19.3 & 4,356 & $<0.001$ \\
\hline $\begin{array}{c}\text { Second strain } \\
1022\end{array}$ & 0.655 & 0.243 & & & & $8.53 \mathrm{e}-15$ & $1.72 \mathrm{e}-01$ & & & & & & \\
\hline T173:T173 & -0.0376 & 0.361 & 1.17 & 4,183 & 0.263 & -1.75 & $2.56 \mathrm{e}-01$ & 13.7 & 4,183 & $<0.001$ & 7.55 & 8,356 & $<0.001$ \\
\hline 1022:T173 & 0.236 & 0.354 & & & & $-4.43 \mathrm{e}-01$ & $2.51 \mathrm{e}-01$ & & & & & & \\
\hline T173:1022 & -0.424 & 0.340 & & & & $-8.24 \mathrm{e}-01$ & $2.41 \mathrm{e}-01$ & & & & & & \\
\hline $1022: 1022$ & -0.528 & 0.342 & & & & $-9.78 \mathrm{e}-15$ & $2.43 \mathrm{e}-01$ & & & & & & \\
\hline
\end{tabular}




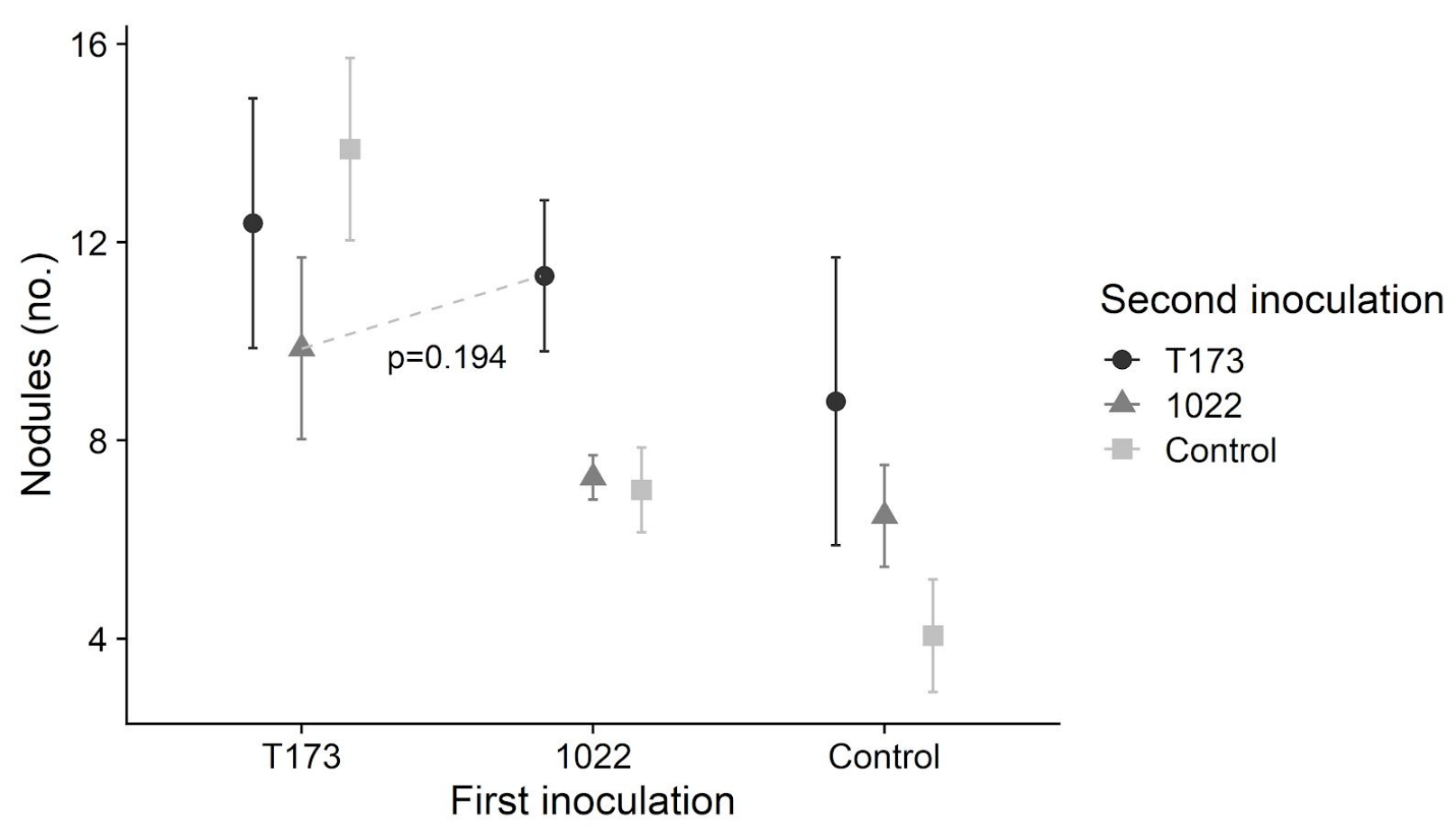

Figure 1. Mean number of nodules $\pm 1 \mathrm{SE}$ formed by plants inoculated with mutualistic Ensifer meliloti strain 1022 (“1022”), ineffective strain Ensifer sp. T173 (“T173”), or a sham inoculation with no bacteria ("Control") at the first (x-axis) and second (symbols in legend) time points. The dotted line compares the T173-1022 and 1022-T173 treatments. 


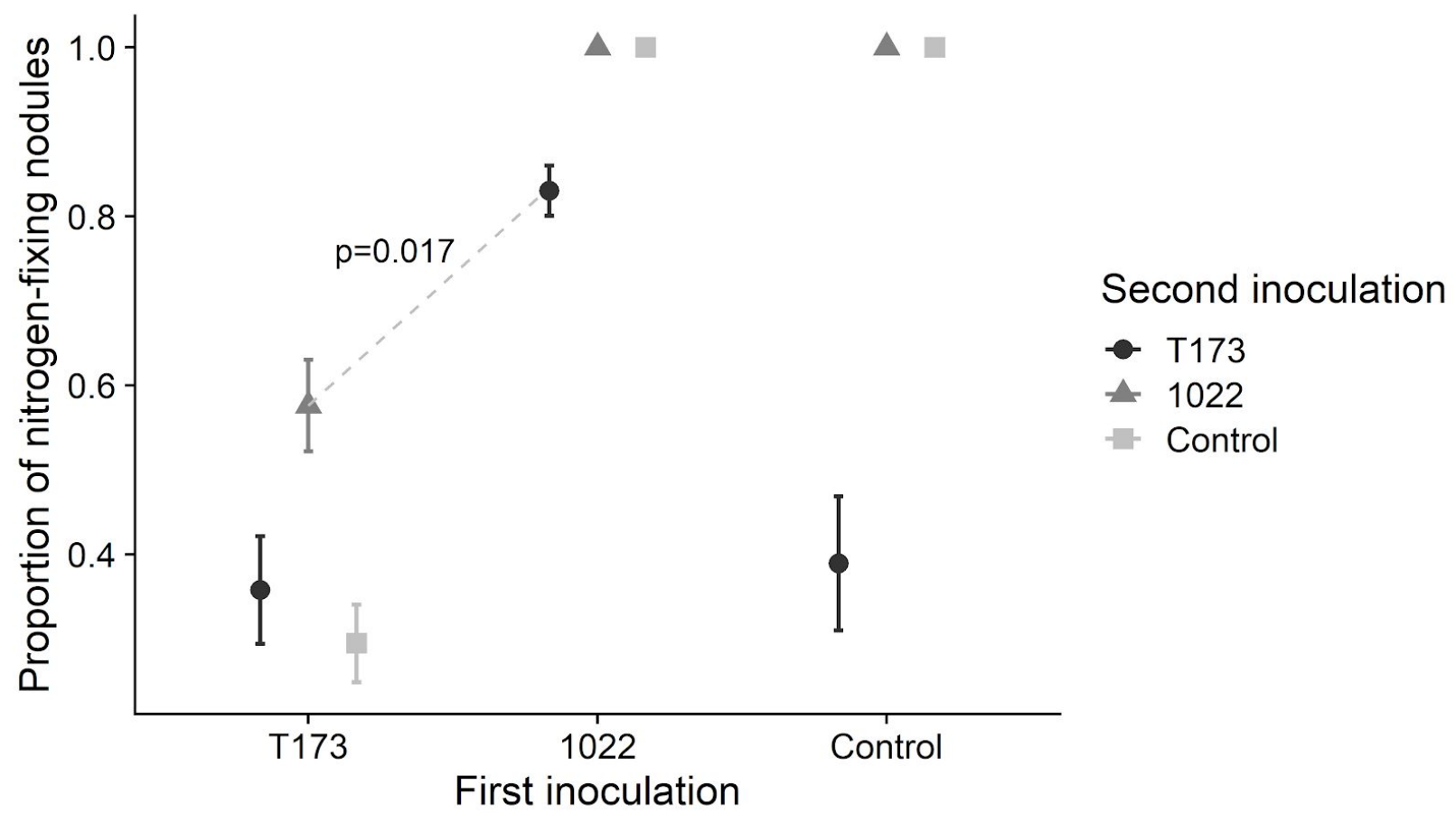

Figure 2. Mean proportion of nitrogen-fixing (i.e., pink) nodules $\pm 1 \mathrm{SE}$ formed by plants inoculated with mutualistic Ensifer meliloti strain 1022 (“1022”), ineffective strain Ensifer sp. T173 (“T173”), or a sham inoculation with no bacteria (“Control”) at the first (x-axis) and second (symbols in legend) time points. The proportion was calculated by dividing the number of effective nodules by the total number of nodules for each plant. Only plants inoculated with T173 made any ineffective (i.e., white) nodules. The dotted line compares the T173-1022 and 1022-T173 treatments using a planned comparison of the number of effective nodules $(\mathrm{p}=0.017)$; the number of ineffective nodules between treatments was also significantly different between these two treatments $(p=0.008)$. 


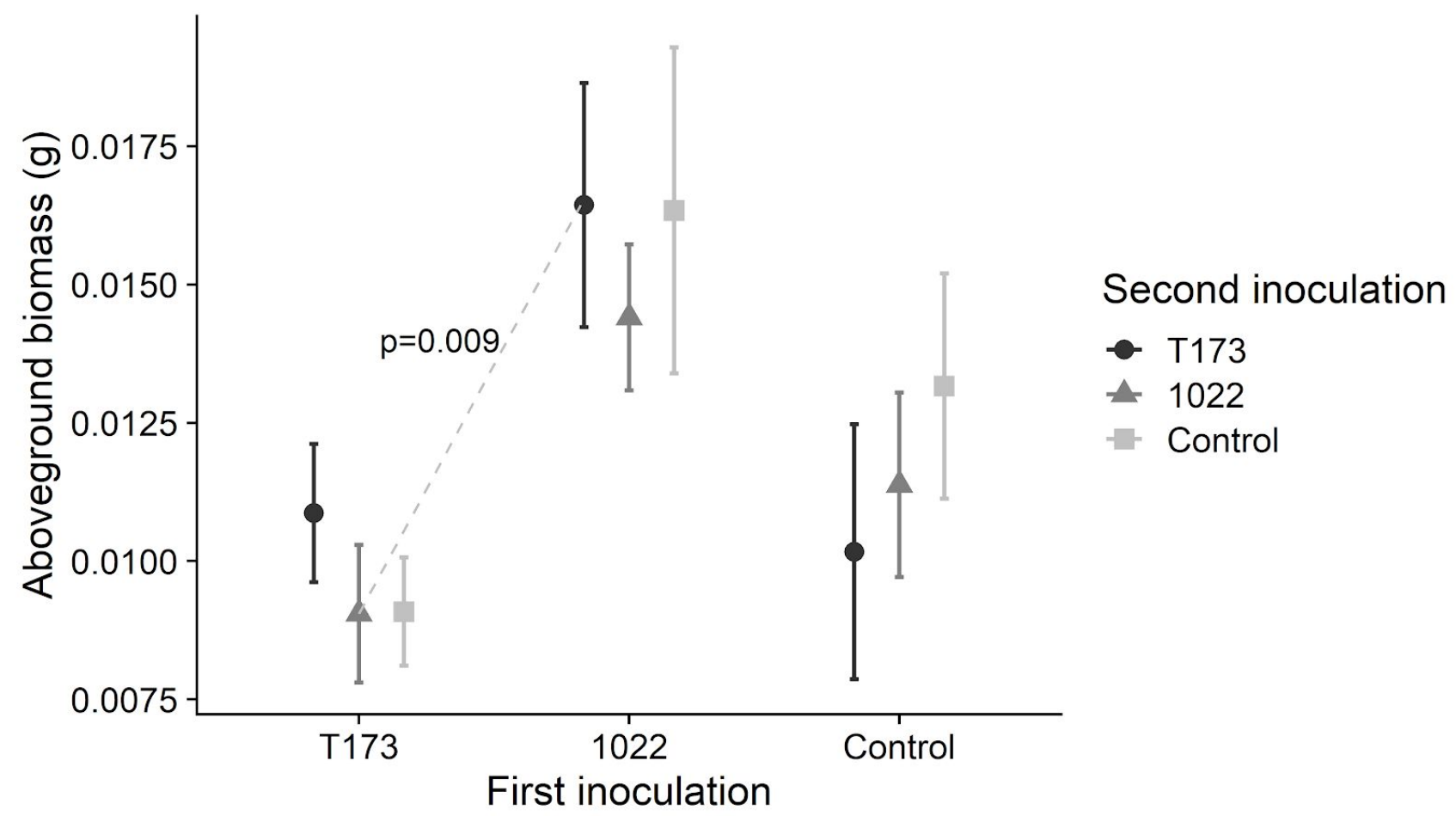

Figure 3. Mean aboveground biomass $\pm 1 \mathrm{SE}$ of plants inoculated with mutualistic Ensifer meliloti strain 1022 (“1022”), ineffective strain Ensifer sp. T173 (“T173”), or a sham inoculation with no bacteria ("Control") at the first (x-axis) and second (symbols in legend) time points. The dotted line compares the T173-1022 and 1022-T173 treatments. 